\title{
The Analysis of Self-Mutilation in Adolescence Based on the Theory of Mentalization: From Sukhvinder in the Novel 'Casual Vacancy'
}

\author{
Mi Ae Oh${ }^{1}$, Chanmin Park', Yeon Jeong Lee ${ }^{2}$, Minha Hong ${ }^{3}$, Ju Hee Han ${ }^{4}$, \\ Soo Hyun $\mathrm{Oh}^{5}$, Jun Heon Park ${ }^{6}$, and Geon Ho Bahn ${ }^{7}$ \\ ${ }^{1}$ Department of Psychiatry, Kyung Hee University Hospital, Seoul, Korea \\ ${ }^{2}$ Department of Psychiatry, Soonchunghyang University Seoul Hospital, Seoul, Korea \\ ${ }^{3}$ Department of Psychiatry, Myongji Hospital, Hanyang University School of Medicine, Ilsan, Korea \\ ${ }^{4}$ Gajoksarang Neuropsychiatric Clinic, Seoul, Korea \\ ${ }^{5}$ Department of Life Sciences, Ewha Womans University, Seoul, Korea \\ ${ }^{6}$ Neomaum Clinic, Ansan, Korea \\ ${ }^{7}$ Department of Psychiatry, Kyung Hee University College of Medicine, Seoul, Korea
}

Objectives: Adolescence involves a number of developmental processes, as well as unique psychological characteristics and behaviors. An increased rate of internet and game addictions, school violence, and suicide may either represent aspects of adolescence or a psychopathological phenomenon. There is an urgent need to develop software programs that can prevent and resolve adolescent behavioral problems. We applied the mentalization theory to interpret and find solutions for problems faced by adolescent characters in literature.

Methods: In Joan Rowling's novel "Casual Vacancy," Sukhvinder is a girl with problems representative of those encountered by modern adolescents; she is a victim of bullying and engages in self-mutilation. We targeted her problematic behaviors as representative of a prementalized state.

Results: Born into an upper-class English family with Pakistani origins, Sukhvinder, unlike her siblings, fails her parents' expectations. Whenever she faces a psychological crisis, she regresses into the teleological mode (the most primitive pre-mentalization stage) and regains her sense of self by cutting herself. After her friend's suicide, however, she begins to communicate with her parents and moves toward mentalization.

Conclusion: By analyzing Sukhvinder's behavior, we assessed patterns of attachment, empathy, and mentalization, and identified corrective approaches for problematic behaviors. We believe that the presented interpretation may serve as a foundation for the development of models for understanding adolescent deviant behaviors.

Key Words: Prementalization; Psychic equivalence; Self-mutilation; Casual Vacancy; Teleological mode; Pretend mode.

Received: May 13, 2019 / Accepted: May 20, 2019

Address for correspondence: Geon Ho Bahn, Department of Psychiatry, Kyung Hee University College of Medicine, 23 Kyungheedae-ro, Dongdaemun-gu, Seoul 02447, Korea

Tel: +82-2-958-8556, Fax: +82-2-957-1997, E-mail: mompeian@khu.ac.kr

\section{INTRODUCTION}

Mental health has recently emerged as the most important issue affecting students in South Korea [1]. Students who ought to be healthy suffer from problems such as cyber-bullying, online game addiction, and self-mutilation, all of which severely undermine educational goals, in addition to high risk of suicide. While it is clearly very important to implement tertiary prevention to reduce the impact once a problem has occurred, it is also important to carry out preliminary interventions where possible by identifying and addressing the cause

This is an Open Access article distributed under the terms of the Creative Commons Attribution Non-Commercial License (https://creativecommons.org/licenses/by-nc/4.0) which permits unrestricted non-commercial use, distribution, and reproduction in any medium, provided the original work is properly cited. of the problem [1]. While a number of programs were designed for primary prevention, there has been little effort made to develop an effective approach towards putting those programs into practice.

Twemlow et al. [2] have developed and applied a program for school violence prevention based on the theory of mentalization, titled "Creating a Peaceful School Learning Environment." This program seeks to strengthen the mentalization skills of both teachers and students by encouraging peer relations within the grade levels, creating a mentor-student relationship between students and local adult volunteers, providing physical exercise through martial arts, and organizing debates which engage all students to share their opinions. These types of programs have been 
successful not only in decreasing school violence, but also in increasing students' learning abilities [3]. In Korea, there is a program entitled "The Mentalization Improvement Program for Adolescents" (MIPAdo) which seeks to apply the theory of mentalization and test its effectiveness in Korean middle school students $[4,5]$. During the development of the MIPAdo program, the creators realized that, while a well-trained program director may be effective, a homeroom teacher who spends time with students and has a special connection to them could be even more impactful. For the program to be successful, it needs to achieve two major aims: it needs to train individuals to become program directors, and it needs to be interesting to students. These goals are important because the program targets all students, not just those with mental health issues. The voluntary and enthusiastic participation of all students is critical.

The authors of this study explored ways of maximizing voluntary participation and took note of "Literature and Medicine" courses introduced to the U.S. medical schools since 1972 to help physicians develop skills in the human dimensions of medical practice [6]. In these courses, students read works of literature and are given a chance to empathize with literary characters; they then put this learned empathy to practical use in their doctor-patient relationships. Literary characters with whose problems and inner conflicts students can empathize and in which they can take an interest can help build a foundation for understanding mentalization and rehabilitation in schools. Rather than scrutinizing students' personal issues and conflicts, analyzing " 3 rd party" literary characters could reduce the students' feelings of resistance and increase their ability to mentalize [7].

In the current study, we have carried out a character analysis using the novel The Casual Vacancy by Rowling [8] and have generated insights for a program on student mental health. Rowling is the author of the internationally renowned "Harry Potter" series. The Casual Vacancy features various delinquent students, whose issues range from substance abuse (cigarettes and marijuana), to dangerous promiscuity, classroom- and cyber-bullying, conflicts with adoptive parents, school violence, self-harm, and suicide. The present study focuses on the character of a young female student, Sukhvinder, who repeatedly engages in self-harm (cutting) and subsequently undergoes a process of self-realization; we attempt to analyze the psychology behind self-harm based on the mentalization theory and propose a therapeutic solution.

\section{METHODS}

In the novel The Casual Vacancy [8], almost all of the events take place in Pagford, a fictional town in England, and por- tray the myriad conflicts that arise when Barry Fairbrother, a selfless local councilman, passes away. His death triggers an election to fill the "casual vacancy" his death creates. The novel presents a diverse cast of adult characters and teenagers whose problematic behaviors accurately capture the struggles faced by modern day adolescents. Sukhvinder Jawanda is a victim of bullying and engages in self-harm, despite the fact that her parents are both successful doctors. Her friend, Krystal, struggles to build a healthy self-image away from her promiscuous past and her crack-addicted mother. Krystal is overwhelmed by guilt and despair when her little brother drowns, and ultimately commits suicide. A classmate named "Fats," a vice schoolmaster's son, breaks school rules out of spite by smoking cigarettes and marijuana from the day he discovers that he was adopted. Andrew endures his father's domestic violence at home while secretly vilifying his father online. Behind all of these characters are troubled homes and parents. In addition to the primary personages listed, there are a numbers of bystanders. In our study, we have identified the common denominator shared by these adolescents as the "Mentalization Development Disorder." A lack of affection from parents and an immature mentalization process during a child's period of growth can lead to a wide range of problems that afflicts many individuals in our society. By examining the homes and parents of children and adolescents, we are able to predict their future.

The current study analyzes the process by which a selfharming victim of bullying, Sukhvinder, recovers her sense of self. We analyze Sukhvinder's conflicts and family situation and study the novel for possible explanations and causes of her symptoms, while at the same time focusing on the role of mentalization. We have singled out Barry Fairbrother, the kindly councilman, who helps the delinquent students to develop "resilience" as the primary agent of recovery. We also analyze the process by which Sukhvinder recovers her selfconfidence through the process of mentalization.

\section{RESULTS}

\section{An introduction to Sukhvinder's family and their internal conflicts}

Sukhvinder Jawanda's family live in the "Old Vicarage," an estate in an upper-class Victorian neighborhood. The mother, Parminder, is a confident and ambitious doctor. At 15 years of age, Parminder discovers that her father had passed away unexpectedly while mowing the lawn, which leaves her traumatized. Although Parminder was her father's favorite, to the dismay of her sisters and mother, she was unable to cry about her father's death, leading the family to perceive her negatively. Parminder develops a deep-seated anger, triggered by 
Sukhvinder and others. The death of Barry Fairbrother, with whom she got along extremely well both personally and politically, places her under enormous stress.

Sukhvinder has two siblings, both of whom outshine her. Jaswant is the older sister, described as a beauty, with luxurious silky hair, a slim waist, high cheekbones, smooth goldenhued skin, and brown eyes. Along with their younger brother, Rajpal, Jaswant consistently places first in her school classes. Vikram, the father, works as a cardiac surgeon at a hospital in the neighboring city of Yarvil; he leads an exemplary social life and has good relationships with his children. Vikram ironically gave Sukhvinder the nickname "Jolly" when she was a baby, because she rarely smiled. Sukhvinder is dyslexic and does poorly in school, often eliciting her mother's wrath. Her father, on the other hand, seems either more forgiving or less caring, perhaps because his other children are such high performers.

Sukhvinder's two siblings have always acted in accordance with Parminder's wishes and plans, but Sukhvinder proves to be a headache for her mother. Parminder is strict and punitive, demanding obedience. She is not sensitive to her children's requests. Her high level of control and low level of affection fit an "authoritarian" parenting style [9]. Children raised by authoritarian parents tend to perform less well in school, to be aggressive, and have low peer ratings and independence when compared to children raised by "authoritative" parents [10].

While Vikram is a successful doctor in the hospital, the way he treats Sukhvinder at home suggests that he "rejects" or "neglects" the child. "Neglecting" parents have little interest in their children's requests, making it more likely that they will fail in the duties of parenthood. Having an "authoritarian" mother and a "neglecting" father may have contributed to Sukhvinder's vulnerability to bullying and her maladjustment to student life. When it comes to the development of executive functions, Sukhvinder seems to have been a "slow to warm up baby" [11].

\section{The mother's ability to mentalize, and insecure attachment}

If any of the subject teachers made the slightest hint that Sukhvinder might try harder, Parminder seized upon it in triumph.

"Sukhvinder is easily discouraged and needs to have more faith in her abilities.' There! You see? Your teacher is saying you don't try hard enough, Sukhvinder."

Parminder said dismissively, "The amount of time you children spend on the internet, I'm surprised you're not in set one" (Rowling, 2012, p.146-147) [8].

"Why? Why? Is this copying the London girl, again- are you trying to impress her? $\mathrm{Jaz}^{1}$ and Raj $\mathrm{j}^{2}$ never behave like this, never-why do you? What's wrong with you? Are you proud of being lazy and sloppy? Do you think it's cool to act like a delinquent? How do you think I felt when Tessa ${ }^{3}$ told me? Called at work-I've never been so ashamed-I'm disgusted by you, do you hear me? Do we not give you enough? Do we not help you enough? What is wrong with you, Sukhvinder?" (Rowling, 2012, p.317-318) [8].

Attachment refers to a person's emotional bonds with another person. Attachment theory is used to explain the attitudes and aspects inherent in all personal relationships $[12,13]$. A child's attachment to his or her mother is the first personal relationship ever formed; whether this attachment is secure or insecure depends on the mother's affection [14]. A child's affection shifts from the parents to peers or a friend of the opposite sex during adolescence as part of the process of developing "autonomy" [15]. Separation from his or her parents does not mean a child will be autonomous on his or her own; autonomy depends on a close and affectionate relationship with the parents. Parenting behavior therefore affects not only early childhood, but also the adolescence [16].

Sukhvinder's mother is not very receptive to other people's thoughts, feelings, or hopes, and lacks flexibility in interpreting their thoughts and feelings. She reaches for and clings to the first conclusion she arrives at, even when it is incorrect. She is a person of inflexible understanding that often emerges in absence of mentalization [17]. Parminder often misinterprets and overgeneralizes the thoughts of a teacher or peer, failing to understand Sukhvinder. When the mother's level of mentalization is low, the child's state of attachment can develop with a "disorganized" structure. Disorganized attachment can lead the child to behave in a contradictory manner towards the parents [18].

\section{A temporary end to mentalization} "Get out of my sight! Go! I'll speak to your father when he comes in-go!" Sukhvinder walked upstairs. Jaswant called from her bedroom: "What was that all that shouting about?" Sukhvinder did not answer. She proceeded to her own room, where she closed the door and sat down on the edge of her bed.

"What's wrong with you, Sukhvinder?

You disgust me.

Are you proud of being lazy and sloppy?"

${ }^{1}$ Older sister

${ }^{2}$ Younger brother

${ }^{3}$ Counselor at school 
What had she expected? Warm encircling arms and comfort? When had she ever been hugged and held by Parminder? There was more comfort to be had from the razor blade hidden in her stuffed rabbit; but the desire, mounting to a need, to cut and bleed, could not be satisfied by daylight, with the family awake and her father on his way.

The dark lake of desperation and pain that lived in Sukhvinder and yearned for release was in flames, as if it had been fuel all along.

Let her see how it feels (Rowling, 2012, p.318-319) [8].

Parminder does not know that Sukhvinder missed class because of bullying and berates her daughter for missing class. When a parent fails to listen carefully to a child's story or cannot empathize properly, the child can feel confused, afraid, guilty, ashamed, and develop low self-esteem [19]. If the child's ability to recognize his or her own emotional state is damaged by stress or extreme lack of parental support, his or her ability to mentalize also suffers and may even temporarily cease [20]. This damages the child's ability to maintain social relationships, and the child may begin to exhibit suicidal ideations, self-harm, or impulsive violence.

\section{Low self-esteem and the psychology of a school violence victim}

Her mind drifted away to Gaia Bawden, the new girl, who had taken such an unaccountable fancy to her. Gaia could have hung out with anyone, with her looks and that London accent, yet she kept seeking out Sukhvinder at lunchtimes and on the bus. Sukhvinder did not understand it. She almost wanted to ask Gaia what she thought she was playing at; day by day she expected the new girl to realize that she, Sukhvinder, was hairy and apelike, slow and stupid, someone to be despised and grunted at and insulted. No doubt she would recognize her mistake soon, and Sukhvinder would be left, as usual, to the bored pity of her oldest friends, the Fairbrother twins (Rowling, 2012, p.149-150) [8].

Sukhvinder was the only person in the room who was making absolutely no noise. With her back hunched and her head bent low over her work, she appeared to be cocooned in concentration. She had pulled the left sleeve of her jumper down so that it completely covered her hand, enclosing the cuff to make a woolly fist. Her total stillness was almost ostentatious.

"The great hermaphrodite sits quiet and still," murmured Fats, his eyes fixed on the back of Sukhvinder's head. "Mustachioed, yet large-mammaried, scientists remain baffled by the contradictions of the hairy man- woman" (Rowling, 2012, p.120) [8].

Of the only class in which Sukhvinder had reached the second set, computing? Fats Wall was not there, so she sometimes dared put up her hand to answer questions (Rowling, 2012, p.147) [8].

The more trauma a young child is exposed to, the higher the chance that the child will become a victim of school violence and suffer from low self-esteem [21]. In Sukhvinder's case, an insecure attachment to her parents and Parminder's unpredictable fits of rage seem to have played a larger role than economic hardship or other sources of trauma. Sukhvinder is unable to respond to the teasing and ostracism because she has low self-esteem caused by poor academic achievement. Ostracism by a large group of children is a common form of school violence and involves a group of children repeatedly and purposefully hurting the victim psychologically and physically. Bullies often push, hit, aggravate, threaten, and spread rumors about the victim [22]. In many cases, the victims are shy, unable to express themselves or communicate well, lacking in social skills and friends, and somewhat neglected by their parents, whether knowingly or otherwise [23]. Sukhvinder also lacks proper guidance from her parents and seems unable to solve her own problems. When the transfer student, Gaia, shows interest in being her friend, Sukhvinder cannot believe that Gaia is serious or sincere.

Recent studies reported that the victims of school bullying exhibit biological and genetic vulnerabilities. Victims tend to exhibit altered cortisol levels, generally higher than average levels found in children, when exposed to stress condition [24]. Genetic studies measuring telomere lengths have shown that bullying victimization is associated with telomere erosion and early childhood stress [25].

\section{Sukhvinder's self-harm: regress into a pre- mentalization state}

She sat up and pulled the razor blade out from a hole in the ear of her old cuddly rabbit. She had stolen the blade from Vikram's store in the bathroom cabinet. She got off the bed and groped for the torch on her shelf, and a handful of tissues, then moved into the furthest part of her room, into the little round turret in the corner. Here, she knew, the torch's light would be confined, and would not show around the edges of the door. She sat down with her back against the wall, pushed up the sleeve of her nightshirt and examined by torchlight the marks left by her last session, still visible, crisscrossed and dark on her arm, but healing. With a slight shiver offear that was a blessed relief in its narrow, immediate focus, she placed the blade halfway up her forearm 
and sliced into her own flesh.

Sharp, hot pain and the blood came at once; when she had cut herself right up to her elbow she pressed the wad of tissues onto the long wound, making sure nothing leaked onto her nightshirt or the carpet. After a minute or two, she cut again, horizontally, across the first incision, making a ladder, pausing to press and to mop as she went. The blade drew the pain away from her screaming thoughts and transmuted it into animal burning of nerves and skin: relief and release in every cut.

At last she wiped the blade clean and surveyed the mess she had made; the wounds intersecting, bleeding, hurting so much that tears were rolling down her face. She might sleep if the pain did not keep her awake; but she must wait for ten or twenty minutes, until the fresh cuts had clotted over. She sat with her knees drawn up, closed her wet eyes, and leaned against the wall beneath the window.

Some of her self-hatred had oozed out with the blood (Rowling, 2012, p.149) [8].

The temporary goal of self-harm is to stabilize the sense of self after a sudden moment of distress, not to display aggression or to attack anyone [20]. In the case of children in the prementalization state of the "teleologic mode," sufferers believe that only physical actions can change the subjective [20]. The visual confirmation of blood and the physical self that exists after self-harm serve to bring validity to the person's existence. In "psychic equivalence mode," self-harm is intended to relieve stress, since a specific part of the body is equated with the problem. Therefore, when the specific part of the body is eliminated or injured, the problem is solved [20]. Both the teleologic and psychic equivalence modes lack a specifically symbolic motive for the act of self-harm; they are merely attempts to stabilize the sense of self. If children feel overly threatened or forced into an extreme emotional state, their ability to monitor themselves decreases, while they themselves fall back into the pretend or teleologic mode [26].

In-Albon et al. [27] carried out a comparison study evaluating female adolescent patients admitted for self-harm, female adolescent patients admitted for other mental ailments, and healthy female adolescents. The patients admitted for self-harm were not suicidal, and the most common method of self-harm was cutting their own skin or wrists. The selfharming patients commonly suffered from comorbid depression and social anxiety, with more than a half exhibiting dependence on cigarettes. Their reported reasons for self-harming were not unlike Sukhvinder's reasons and included the following: "to escape a feeling of rejection," "to reduce pressure from social relationships," and "to feel better." These reasons coincide with the diagnostic standards of "non-suicidal selfinjury" listed in the Diagnostic and Statistical Manual of Mental Disorders (DSM)-5 [28].

\section{A good enough internal working model}

She (Krystal) heaved on the handle, making a stupid face at Nikki and Leanne, and everyone laughed again.

"Look at that," Barry had said, beaming. "She's a natural."

Had Krystal really been a natural? Tessa did not know anything about rowing; she could not tell.

"Straighten your back," Barry told Krystal, "or you'll injure it. That's it. Pull...pull...look at that technique... have you done this before?"

Then Krystal really had straightened her back, and she really had done it properly. She stopped looking at Nikki and Leanne. She hit a rhythm.

"Excellent," said Barry. "Look at that...excellent. That's how you do it! Atta girl. And again. And again. And-" (Rowling, 2012, p.314) [8].

What was it that Barry had had? He was always so present, so natural, so entirely without self-consciousness. Teenagers, Tessa knew, were riven with the fear of ridicule. Those who were without it, and God knew there were few enough of them in the adult world, had natural authority among the young; they ought to be forced to teach (Rowling, 2012, p.315) [8].

(Parminder remembered what she had said to Sukhvinder a couple of nights previously. "Krystal Weedon! That stupid Girl! Is that what being in a team with Krystal Weedon taught you - to sink to her level?"

Barry had liked Krystal. He had seen things in her that were invisible to other people's eyes.

(ellipsis) She had called Krystal Weedon stupid and implied that she was low.

Barry would never have said it.

She was ashamed.) (Rowling, 2012, p.342) [8].

Barry, in addition to being a local councilman, is also the coach of a rowing team at Sukhvinder's school; he created this team, personally training the rowers, and driving them to the races. Even delinquent students like Krystal enjoy being a part of the rowing team because Barry encourages them. After his death, the school authorities decide to disband the team. Barry was unaffected by the cynical criticisms he attracted for recruiting delinquent students into the rowing team. Instead, he was able to focus on the delinquent students' strengths. Parminder realizes that this is the difference between herself and Barry. She judged Krystal based on her own 
standards, categorizing Krystal as a "stupid girl" and regarding her as someone of "lowly or humble condition," while Barry did not. By contrast, Barry's attitude functions as an excellent internal working model for adult relationships, as well as parent-child relationships. Fonagy and Target [29] report a generational transfer of forms of attachment. In other words, the child's ability to mentalize will mirror that of his or her parents. An increase in the mother's ability to mentalize is likely to help her control negative feelings, reduce her depressive and anxious tendencies, and stabilize a healthier relationship with her children [30].

\section{Moment of mentalization for both Krystal and Sukhvinder}

And then Krystal, bringing up the rear of the group with Sukhvinder, had called her a silly Paki bitch.

It had come out of nowhere. They had all been messing around with Mr. Fairbrother. Krystal thought she was being funny. She used "fucking" interchangeably with "very," and seemed to see no difference between them. Now she said "Paki" as she would have said "dozy" or "dim." Sukhvinder was conscious of her face falling, and experienced the familiar sliding, scalding sensation in her stomach.

"What did you say?"

Mr. Fairbrother had wheeled around to face Krystal. None of them had ever heard him properly angry before.

"Idi'n mean nuthin," said Krystal, half taken aback, half defiant. "I was on'y jokin." She knows I was jus' jokin." Don' yeh?" she demanded of Sukhvinder, who muttered cravenly that she knew it was a joke.

"I never want to hear you use that word again."

They all knew how much he liked Krystal. They all knew he had paid for her to go on a couple of their trips out of his own pocket. Nobody laughed louder than Mr. Fairbrother at Krystal's jokes; she could be very funny.

They walked on, and everybody was embarrassed. Sukhvinder was afraid to look at Krystal; she felt guilty, as she always did.

They were approaching the people carrier when Krystal said, so quietly that even Mr. Fairbrother did not hear it: "I wuz just jokin."

And Sukhvinder said quickly, "I know."

"Yeah, well. S'ry."

It came out as a mangled monosyllable, and Sukhvinder thought it tactful not to acknowledge it. Never-

${ }^{4}$ Since its appearance in British newspapers in the 1960s, Paki was a racist term disparaging people from the former British colony. Since then, it has been used as a word to describe people from the southern Asian regions where includes India, Afghanistan, and Bangladeshi. theless, it cleaned her out. It restored her dignity (Rowling, 2012, p.148) [8].

Barry holds an unquestioned authority over the team of delinquent students. Krystal may be the athlete he values the most, but when she throws a demeaning comment at Sukhvinder, he does not hesitate to berate her. Even more importantly, he does not demand an apology from Krystal. He gives Krystal the chance to realize her own fault and apologize. A demand for apology or reflection, even if well intentioned, often turns into criticism if the perpetrator does not accept his or her fault [31]. Barry's actions reflect "authoritative discipline" instead of "authoritarian discipline" [9]. "Authoritative discipline" is characterized by high levels of affection and control. Parents who fall into this category carefully observe the actions of their children and support their decisions, preferring to resolve conflicts through conversation. These parents do not stop at explaining "why" a child has to behave in a certain way. Instead, they focus on creating conversations that help the child understand the consequences of his or her behavior [32].

A state of mind that does not belong to one's own may represent a state that inherits the malicious intent of another person who bothers or offends one [20]. Providing an opportunity to create and maintain a relationship with others is the foundation of mentalization treatment [20]. Seeing Barry admonish Krystal gives Sukhvinder an opportunity to feel respected and treated fairly, helping her realize that her own perception of herself may be too harsh. The fact that Barry recognizes the anger she feels and is able to admonish Krystal with an authority that Sukhvinder herself is unable to muster serves as an example of a good internal working model. If Sukhvinder had been exposed to such good models more often, she herself would have a better internal working model and would have been able to cope with and walk away from her self-harming behavior.

\section{Moment of mentalization for Sukhvinder, Parminder, and Vikram}

At the hospital, they made her undress again, but this time her mother was with her in the curtained cubicle, and she realized her mistake too late when she saw the expression of horror on Parminder's face.

"My God," she said, grabbing Sukhvinder's forearm. "My God. What have you done to yourself?"

Sukhvinder had no words, so she allowed herself to subside into tears and uncontrollable shaking, and Vikram shouted at everyone, including Parminder, to leave her alone, but also to damn well hurry up, and that her cut needed cleaning and she needed stitches and sedatives and $X$-rays... 
Later, they put her in bed with a parent on each side of her, and both of them stroked her hands. She was warm and numb, and there was no pain in her leg anymore (Rowling, 2012, p.473) [8].

When a psychoanalyst hits the mark with a patient, the patient tends to remain silent or exclaim "Aha!," or "Yes, that's it!" Stern et al. [33] calls this a "moment of meeting," Benjamin [34] calls it "the moment of truth," and Fogel [35] calls it the "momentum of treatment." When Sukhvinder's parents see her scars for the first time, they recognize that their parent-child relationship with Sukhvinder is flawed, and "affect attunement" takes place rapidly. Sukhvinder also recognizes the terror in her mother's face and realizes that self-harm is wrong, in a rapid development of mentalization.

\section{Epilogue: from spectator to active participant after mentalization}

It was Sukhvinder Jawanda who had chosen the bright pink coffin for Krystal, as she was sure she would have wanted. It was Sukhvinder who had done nearly everything; organizing, choosing and persuading. Parminder kept looking sideways at her daughter, and finding excuses to touch her: brushing her hair out of her eyes, smoothing her collar (Rowling, 2012, p.495496) [8].

Fonagy's study concludes that the mother's ability to mentalize induces regular and sensitive reactions from the child, and has a direct relationship with child rearing [36]. After connecting with her parents, the previously shy and inactive Sukhvinder transforms into a proactive and energetic girl. Mentalization has the ability to magnify personal strengths [36].

\section{DISCUSSION}

Despite Freud's objections, psychoanalyzing a work of art provides an indirect route toward understanding universal aspects of human psychology [37]. Examining literary works and movies allows researchers to confirm the results of clinical studies. It is difficult to carry out follow-up studies that monitor a patient's environment and symptoms over his or her whole lifespan. However, it is possible to experience lifelong changes in humans through the development of main characters in literary works, and to infer the optimal therapeutic intervention or prognosis. Good works of art not only bring delight, but also provide an opportunity to examine the development of the human unconscious [7].

Sukhvinder in The Casual Vacancy is not unlike the "ugly duckling," a solitary figure within both her school and her family. The current study has examined the processes through which her ability to mentalize seemed to temporarily stop or even regress. The ability to mentalize is the ability to empathize with and accommodate other people; it acts as a highly developed emotional stabilizer and introspective tool. The core tenet of mentalization is the ability to view any event from a psychological perspective and to understand its symbolic importance. This accomplishment allows for the contextualization of relationships in certain situations [38]. Mentalization has a direct relationship with secure attachment in early childhood; it increases when the parent is careful to empathize with and respect the child. The ability to mentalize also protects the individual from mental trauma [36]. Sukhvinder experiences repeated traumatic experiences and chooses "self-harm" as a solution because she has regressed from a state capable of mentalization.

The concept of "self-harm" differs from scholar to scholar. Freud [39] asserted that self-harm resulted from an animalistic death instinct, or thanatos. Menninger [40] viewed selfharm as a way to avoid suicide by committing a "partial-suicide." Stengel [41] considered self-harm and suicide two completely different acts. Graff and Mallin [42] referred to wrist-cutting as a non-suicidal act of self-stabilization. Pao [43] used the term "delicate self-cutting," while Ross and McKay [44] also viewed self-harm and suicide as two completely different acts, given that self-harm is non-suicidal. Favazza [45] defined self-harm as a non-suicidal modification of one's own body. Various others have voiced divergent opinions, but the majority agrees that suicide seeks escape through death, while self-harm is rooted in the healthier urge to return to a "normal" state. However, DSM-5 categorizes non-suicidal selfinjury as a "condition for further study," acknowledging past debate regarding the difference between suicide and selfharm and encouraging further clinical study [28]. Sukhvinder's self-harming behavior stems from a desire to protect herself. Although in her regressed state of pre-mentalization, self-harming might seem like an optimal solution, this behavior is universally considered as unhealthy. Sukhvinder realizes this and comes to understand that her mother loves her deeply when she witnesses Parminder's reaction to her scars.

Sukhvinder's journey to overcome both self-harm and ostracism position the character to serve as an effective role model and demonstrate how to cope with and confront various difficulties faced by many contemporary students. A practical example of the value of literary works can be found in the virtual patients (VPs), used in the medical education system [6]. Although Deladisma et al. [46] consider professionally trained, simulated patients more effective at delivering empathy training to medical students, the difficulties in- 
volved in recreating realistic scenarios for human actors (as well as the cost of hiring them) make VPs a much more viable option. Computer programs using VPs can simulate a medical situation; a situation like Sukhvinder's case can be used to develop an interactive program to educate adolescent students about mental health issues, including self-mutilation. Expertise in the department of education can be harnessed to design VPs for incredibly diverse contexts. Once completed, VPs do not require time, personnel, or usable space. A wellprogrammed VP does not require a program coordinator or supervisor. It can be used to educate students through its interactive nature. Further research is necessary to create VPs based on Sukhvinder's character, as well as characters from Korean literature.

The current study is limited by the lack of objective information about Sukhvinder. The only available information is provided by the author and lacks the insights that could be obtained from a third party to provide or confirm their objectivity. The novel, The Casual Vacancy, also does not fully develop the character of Barry, who is an example of a healthy internal working model for the delinquent adolescents. Additionally, we have to keep in mind that the mentalization process that Sukhvinder undergoes may differ from reality, because it takes place in a setting which reflects the writer's intention. Despite these limitations, the current study is the first attempt to analyze a literary character using mentalization theory in order to optimize mental health programs for adolescents.

\section{CONCLUSIONS}

Much in the same way that we have focused on The Casual Vacancy, the vast diversity of literature holds incredible potential for the creation of varied therapy and rehabilitation programs. The results of the current study can introduce new perspectives to the programs currently used to develop physically and mentally healthy students. The analysis of literary characters can deepen our current understanding of attachment, empathy, self-reflection, and the ability to mentalize, helping troubled adolescents and even anticipating problems likely to arise in early adulthood.

\section{Acknowledgments}

This study was supported by the research fund from the Korean Association of Psychoanalysis on 2013.

This article was published in Korean language in the Journal of the Korean Association of Psychoanalysis, titled as "Psychoanalysis" 2014; 25(1):24-32. Professor Jee-Hyun Ha, the editor-in-chief of "Psychoanalysis" has agreed to publish this article as secondary publication in English. The editor-in-chief of the journal also agreed with its secondary publication in English. Although the title and content of the orig- inal article written in Korean have not been modified beyond the translation, the authors' affiliations have been updated to reflect their current institutions. Abstracts and conclusions were modified to meet the formatting requirements of this journal. Additionally, a small number of references (reference 6, 11, 24, and 25) have been added and one replaced (reference 9) to the citations. While the number of references cited in this paper exceeds the 30 recommended in the guidelines of this journal, the editorial committee has accepted the article in the form in which it was published in 'Psychoanalysis'.

Authors thank Edward Kim for his efforts with the translation of this article from Korean into English.

\section{Conflicts of Interest}

The authors have no potential conflicts of interest to disclose.

\section{REFERENCES}

1) Bahn GH, Choi YS. The role of physicians in preventing school bullying. J Korean Med Assoc 2013;56:554-558.

2) Twemlow SW, Fonagy P, Sacco FC, Gies ML, Evans R, Ewbank R. Creating a peaceful school learning environment: a controlled study of an elementary school intervention to reduce violence. Am J Psychiatry 2001;158:808-810.

3) Twemlow SW, Fonagy P, Sacco FC. An innovative psychodynamically influenced approach to reduce school violence. J Am Acad Child Adolesc Psychiatry 2001;40:377-379.

4) Oh SY, Moon SJ, Lee WH, Hong MH, Min JW, Kim BS, et al. Efficacy of the Short Form of Mentalization Improvement Program for Adolescent (MIPAdo) for enhancement of mental health in school children. J Korean Acad Child Adolesc Psychiatry 2012;23:117-126.

5) Moon SJ, Oh SY, Lee WH, Hong MH, Min JW, Kim BS, et al. Efficacy of the Mentalization Improvement Program for Adolescent (MIPAdo) for enhancement of mental health in school children. J Korean Acad Child Adolesc Psychiatry 2012;23:109-116.

6) Bahn GH, Kwon T, Hong M. Empathy in medical education. In: Watt DF, Pankwepp J, editors. Psychology and Neurobiology of Empathy. New York: Nova Science Publishers, Inc;2016. p.229-258.

7) Lee SY, Moon DS, Chung US, Bahn GH. Harry Potter's pensieve and the unconscious. Psychoanalysis 2013;24:92-101.

8) Rowling JK. The casual vacancy. London: Hachette;2012.

9) Baumrind D. Patterns of parental authority and adolescent autonomy. New Dir Child Adolesc Dev 2005;108:61-69.

10) Thompson A, Hollis C, Dagger DR. Authoritarian parenting attitudes as a risk for conduct problems results from a British national cohort study. Eur Child Adolesc Psychiatry 2003;12:84-91.

11) Thomas A, Chess S. An approach to the study of sources of individual differences in child behavior. J Clin Exp Psychopathol 1957; 18:347-357.

12) Bowlby J. The making and breaking of affectional bonds. I. Aetiology and psychopathology in the light of attachment theory. An expanded version of the Fiftieth Maudsley Lecture, delivered before the Royal College of Psychiatrists, 19 November 1976. Br J Psychiatry 1977;130:201-210.

13) Bowlby J. The making and breaking of affectional bonds. II. Some principles of psychotherapy. The fiftieth Maudsley Lecture. Br J Psychiatry 1977;130:421-431.

14) Ainsworth MD, Blehar MC, Waters E, Wall SN. Patterns of attachment: a psychological study of the strange situation. Oxford, England: Lawrence Eribaum;1978.

15) Allen JP, Hauser ST, Bell KL, O'Connor TG. Longitudinal assessment of autonomy and relatedness in adolescent-family interactions as predictors of adolescent ego development and self-esteem. Child Dev 1994;65:179-194.

16) Noh KS, Huh MY, Hong HJ. A study of relationship between ado- 
lescent attachment patterns and parenting behaviors. J Korean Neuropsychiatr Assoc 2003;42:116-123.

17) Slade A, Grienenberger J, Bernbach E, Levy D, Locker A. Maternal reflective functioning, attachment, and the transmission gap: a preliminary study. Attach Hum Dev 2005;7:283-298.

18) Main M, Solomon J. Procedures for identifying infants as disorganized/disoriented during the Ainsworth Strange Situation. In: Greenberg MT, Cicchetti D, Cummings EM. Attachment in the Preschool Years: Theory, Research, and Intervention. Chicago: University of Chicago Press;1990. p.121-160.

19) Ahn MH. Maternal insecure adult attachment and child behavior problem: mediating role of maternal emotion and psychological control. Kor J Psychol 2010;29:867-885.

20) Bateman A, Fonagy P. Mentalization-Based Treatment for Borderline Personality Disorder: A Practical Guide. Oxford: Oxford University Press;2006.

21) Humphreys J, Epel ES, Cooper BA, Lin J, Blackburn EH, Lee KA. Telomere shortening in formerly abused and never abused women. Biol Res Nurs 2012;14:115-123.

22) Dawkins J. Bullying in schools: doctors' responsibilities. BMJ 1995; 310:274-275.

23) Choi YJ, Jhin HK, Kim JW. A study on the personality trait of bullying \& victimized school children. J Child Adolesc Psychiatry 2001; 12:94-102.

24) Knack JM, Jensen-Campbell LA, Baum A. Worse than sticks and stones? Bullying is associated with altered HPA axis functioning and poorer health. Brain Cogn 2011;77:183-190.

25) Shalev I, Moffitt TE, Sugden K, Williams B, Houts RM, Danese A, et al. Exposure to violence during childhood is associated with telomere erosion from 5 to 10 years of age: a longitudinal study. Mol Psychiatry 2013;18:576-581.

26) Bahn GH. From attachment theory to mentalization: historical background and clinical implications. Psychoanalysis 2013;24:9-20.

27) In-Albon T, Ruf C, Schmid M. Proposed diagnostic criteria for the DSM-5 of nonsuicidal self-injury in female adolescents: diagnostic and clinical correlates. Psychiatry J 2013;2013:159208.

28) American Psychiatric Association. Diagnostic and Statistical Manual of Mental Disorders: DSM-5. Washington, DC: American Psychiatric Association;2013.

29) Fonagy $P$, Target $M$. Bridging the transmission gap: an end to an important mystery of attachment research? Attach Hum Dev 2005; 7:333-343.
30) Lee HJ, Ahn MH. Maternal insecure adult attachment and psychological control: mediating role of mentalization and negative emotion. Kor J Woman Psychol 2012;17:413-434.

31) Fonagy P, Target $M$. Attachment and reflective function: their role in self-organization. Dev Psychopathol 1997;9:679-700.

32) Pratt MW, Kerig P, Cowan PA, Cowan CP. Mothers and fathers teaching 3-year-olds: authoritative parenting and adult scaffolding of young children's learning. Dev Psychol 1988;24:832-839.

33) Stern DN, Sander LW, Nahum JP, Harrison AM, Lyons-Ruth K, Morgan AC, et al. Non-interpretive mechanisms in psychoanalytic therapy. The 'something more' than interpretation. The Process of Change Study Group. Int J Psychoanal 1998;79:903-921.

34) Benjamin J. Escape from the hall of mirrors: commentary on paper. Psychoanal Dialogues 2004;14:743-753.

35) Fogel GI. Discussion: some aspects of compliance in psychoanalytic treatment. Psychoanal Inq 1999;19:97-113.

36) Fonagy P. Attachment Theory and Psychoanalysis. New York: Other Press; 2001.

37) Ha JH. A psychodynamic exploration of creativity of Steven Spielberg: focused in recent 3 movies. Psychoanalysis 2003;14:105-115.

38) Bouchard MA, Target M, Lecours S, Fonagy P, Tremblay LM, Schachter A, et al. Mentalization in adult attachment narratives: reflective functioning, mental states, and affect elaboration compared. Psychoanal Psychol 2008;25:47-66.

39) Freud A. Adolescence. Psychoanal Study Child 1958;13:255-278.

40) Menninger KA. Man against Himself. New York: Harcourt, Brace; 1938.

41) Stengel E. Suicide and Attempted Suicide. Oxford: Penguin Books; 1964.

42) Graff H, Mallin R. The syndrome of the wrist cutter. Am J Psychiatry 1967;124:36-42.

43) Pao PN. The syndrome of delicate self-cutting. Br J Med Psychol 1969;42:195-206.

44) Ross RR, McKay HB. Self-Mutilation. Lexington, MA: Lexington Books; 1979.

45) Favazza AR. Bodies Under Siege: Self-Mutilation and Body Modification in Culture and Psychiatry. 2nd ed. Baltimore: Johns Hopkins University Press; 1996.

46) Deladisma AM, Cohen M, Stevens A, Wagner P, Lok B, Bernard T, et al. Do medical students respond empathetically to a virtual patient? Am J Surg 2007;193:756-760. 